\title{
E-Assessment as a Vector for Identifying and Increasing the Validation of Advice Within Professional Organizations
}

\author{
https://doi.org/10.3991/ijim.v14i20.15663 \\ Yassir Aichi $\left.{ }^{(}\right)$, Mustapha Bassiri, Said Benmokhtara, \\ Said Belaaouad \\ Hassan II University of Casablanca, Casablanca, Morocco \\ yassiraichi@gmail.com
}

\begin{abstract}
The particularity of E-Assessment is that it allows combining the assessment of personality with that of personal and interpersonal values. It is this joint assessment that makes all the richness and interest of digital assessment for human resources professionals in terms of recruitment, career management, professional orientation, and assessment of soft skills. The platforms dedicated to evaluation cover several families: behavioral tests or personality tests, aptitude tests, and value questionnaires. They have the particularity to measure with a certain precision dimension denied by the editor, in connection with scientific concepts. Then they statistically compare the results to a standard and a reference population. To assess the impact of E-Assessment, we opted during this study at SOSIE 2nd Generation for a digital HR tool that meets the current requirements of human resources professionals for assessment in international contexts. Indeed, the work was carried out on the content of the items, the dimensions, the descriptive and interpretation reports through reading in terms of percentiles, common behavior styles for a population of Moroccan professionals operating in various sectors of activity. The objective of this article is to study the contribution of the E-assessment on the assessment of the personality and the value system of Moroccan executives within professional organizations and their impact on decision-making. The results obtained after using the Sosie tool demonstrate that the use of the e-assessment has become a primordial action in professional circles to guarantee the obtaining of a real map of managerial skills.
\end{abstract}

Keywords-E- Assessment; Soft Skills; 2nd Generation SOSIE; Behavioral tests; Human Resources

\section{Introduction}

E-Assessment is a photograph of the reality perceived by the entourage and takes into account two crucial aspects: know-how (skills, determines the efficiency and performance of an individual for a given job), and the know-how to be (behavior, attitude, ability to collaborate with your team, managerial address, etc.). This type of assessment is mainly intended for managers, executives, and project managers. To be relevant, the 
digital evaluation can only be carried out for people with 1 or even 2 years of seniority. The idea is to collect the opinions of the manager's professional entourage. Questionnaires are generally anonymous. To predict an employee's performance, aptitude tests are one of the most predictive assessment tools for long-term professional success. By evaluating cognitive skills (memory, logical reasoning, multitasking, etc.), the e-assessment makes it possible to have an effective diagnosis of employees. Personality tests make it possible to detect the talents of candidates and their suitability for the targeted position. The in-depth analysis using the E-assessment presents the candidate's potential and his areas of development. Suitability report reconciles his profile with a benchmark of behaviors required for a specific position. It details its strengths and weaknesses for the position and gives examples of interview questions.

The use of SOSIE platform is justified by the fact that it combines the assessment of personality and that of personal and interpersonal values. It is this common assessment that makes all the wealth and interest of SOSIE for Human Resource professionals in terms of recruitment, career management, professional orientation, skills and training evaluation. While the personality assessment provides information about a person's resources, potential, strengths and developmental needs, the assessment of their values highlights their motivations, sources of satisfaction and commitment.

This work undertaken since 2017 on the SOSIE had as main objectives: to offer an international vision with national standards on Moroccan managers and executives and "international" standards allowing cross-cultural comparisons and leaving users the choice of standards according to the context of the application. These standards will be enriched with new national data from other countries.

In this article, we specifically examine the technical processes active in the instruction of the SOSIE platform and the uses that professionals can make of this complete platform as part of a strategic diagnostic intervention of organizations.

\section{The Review of Literature}

E- Assessment combines the three classic tests developed by Leonard V. Gordon, a prominent American psychologist, namely: Gordon's personality inventory (GPPI, 1978) [1]. This questionnaire was published in 1953 and has had several successive versions. It measures eight personality traits and combines two instruments: The Gordon Personal Profile (GPP) [2]. and the Gordon Personal Inventory (GPI). Cattell's $(1947,1948)$ research on personality scales is particularly relevant, and six factors stemming from this research have been taken into account in the development of this tool (Gordon, 1953; Gordon, 1956). Two of the four dimensions of GPI (Circumspection et Dynamism) were already present in Cattell's previous factor analyzes (1947, 1948). All four had been reconfirmed in Thurstone's 1951 factor analysis of dimensions. The inventory of personal values (SPV, 1967) [3]. First published in 1967, it measures six personal values. The inventory of interpersonal values (SIV, 1975) [4]. Published in 1960, it measures six interpersonal values.

E-assessment refers to the end-to-end electronic assessment process in the which the ICT is used for the presentation of recording responses and assessment activities [5]. 
E-assessment tends to analyze the prior cognitive level of the learner, and based on this analysis it proposes the next proper assessment activity [6]. E-Assessment system must provide accurate and objective assessment as the traditional assessment. Additionally, the system must be reliable and available during the assessments in order to finish the assessment in a proper time [7].

\subsection{Definition of dimensions}

E- Assessment describes people in two different ways:

The first concerns personality traits: these are relatively stable characteristics, which influence individual behavior. They can also be described as the resources specific to a person, the potentials that he will put at the service of his professional activity. These Personality traits interact with each other and indicate the type of work for which the person is best suited. They evolve relatively little, although situations, particular environments, or accidents of life can affect them. The person can also be described in terms of their motivations, which stem from their underlying values. Values are driving forces, sources of motivation, or mobilization that have a large impact on a person's reactions or behaviors at work.

Values are linked to an ideal form and influence people's expectations in terms of work and the environment. The work environment, the culture of the company can allow the satisfaction of certain expectations. Sometimes there can be incompatibility or conflict: performance and success will be affected. SOSIE assesses values that relate to the person's behavior (personal values) and values that relate to their mode of interaction with others (interpersonal values).

\section{$3 \quad$ Methodology Preconized}

Competence becomes a resource like any other, which must be managed; it is considered strategic, a source of value and performance. The quality and use of skills must be mastered, and their value must be judged through evaluation, in order to develop, value and reward them. The notion of competence is abstract, that there are competent people in certain situations, in a certain work organization. Whether or not it is this organization of work that will promote initiative and the emergence of skills, and not the sole employee. This has the consequence of considering the assessment as a reflection on what promotes or hinders the building of skills.

Context of the assessment also changes depending on organizational changes, a focus on the manager's individual skills, career and salary individualization. It is also a matter of not confusing performance and competence, where one sign the efficiency of the individual through his actions, and the other the social appreciation of efficiency. Indeed, the judgment of competence is nourished by other elements than the only evaluation of the performance. In order to have a better judgment, we opt for the SOSIE eassessment. SOSIE is the most widely used personality inventory in professional circles. It provides Human Resources professionals with information on the personality, values, or sources of the motivation of the person. It thus makes it 
possible to identify the dynamics of a person, to identify the agreement or possible discrepancies between the characteristics of the proposed position and the motivations and professional behaviors of the person. The only inventory to jointly assess personality and values, SOSIE assesses the decisive dimensions in terms of professional behavior. SOSIE platform is rigorous, the tools adapted, the measurement system is precise and the restitution is detailed. this digital platform makes it possible to highlight the strengths and areas for improvement, differences in perception, as well as the person's management and leadership style. It provides areas for behavioral progress, gives the direction in which to evolve. It includes the retrospectively observable results and the managerial behaviors implemented to obtain them. Considered as a tool for change rather than a control tool, it allows for the confrontation of several points of view.

Measuring personality and values is therefore very important in assessing a person. SOSIE not only detects certain behaviors potentially adapted or unsuitable for a position or a function, but it also detects what types of situations and environments can motivate (or demotivate) a person, and thus encourage (or not) behaviors specific to achieving excellent performance. It, therefore, provides relevant data which is not taken into account in conventional personality tests and which can help to adapt development plans, recruitment, promotion, career, and counseling decisions. SOSIE profile of the candidates was calculated from the answers provided during the handover which lasted on average 00:40:24 minutes. The scores obtained at the dimensions were transformed into percentiles using the Moroccan - Adult Active calibration.

This transformation makes it possible to indicate the proportion of the reference population having a score lower or equal to that of the candidates in terms of percentages (for example, the percentile 34 means that $34 \%$ of people in the Moroccan - Adult Active classification. $L$ he interpretation of the results is done in terms of low $(<=30$ percentile), medium (31 to 70 percentile) or high ( $>=71$ percentile) zones. The information in this report allows you to make assumptions, which must be confirmed or denied during the restitution interview.

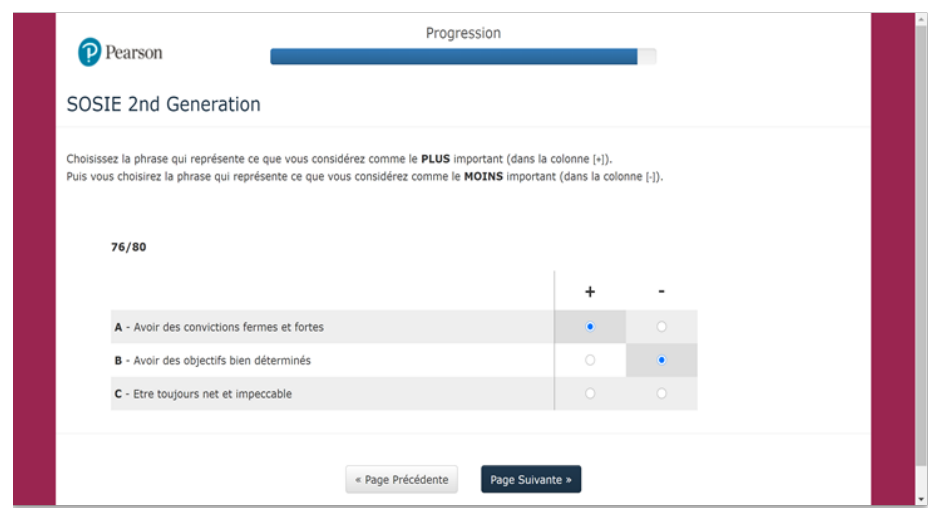

Fig. 1. Question interface - Sosie 2nd Generation (French version) 


\subsection{Analysis and discussion of the results}

The French version of the SOSIE was administered online and under supervised administration conditions. A sample of 778 people exercising supervisory functions in different branches $(42.2 \%$ women and $57.8 \%$ men, average age 39 years and standard deviation 8) completed the SOSIE questionnaire in supervised mode and a professional context (selection or personal development). The descriptive statistics for this sample are presented in Table 11.

Table 1. Descriptive statistics - Moroccan sample $(\mathrm{N}=778)$

\begin{tabular}{|l|c|c|}
\hline \multicolumn{1}{|c|}{ Scales } & Average & Standard deviation \\
\hline 1. Dominance & 19.6 & 4.4 \\
\hline 2. Perseverance & 23.4 & 3.3 \\
\hline 3. Resistance to stress & 20.8 & 4.2 \\
\hline 4. Sociability & 17.2 & 3.9 \\
\hline 5. Circumspection & 20.2 & 4.0 \\
\hline 6. Curiosity of mind & 23.0 & 3.7 \\
\hline 7. Acceptance of others & 19.0 & 4.0 \\
\hline 8. Dynamism & 21.9 & 3.8 \\
\hline 9. Search for approval & 9.7 & 3.4 \\
\hline 10. Conformism & 10.2 & 4.3 \\
\hline 11. Social consideration & 7.9 & 3.2 \\
\hline 12. Freedom of action & 12.1 & 3.8 \\
\hline 13. Interest in others & 18.6 & 3.4 \\
\hline 14. Taste of power & 13.6 & 4.4 \\
\hline 15. Materialism & 8.3 & 3.7 \\
\hline 16. Personal challenge & 14.3 & 4.0 \\
\hline 17. Variety / Novelty & 12.4 & 5.2 \\
\hline 18. Conviction & 12.5 & 4.1 \\
\hline 19. Organization / Method & 10.9 & 4.4 \\
\hline 20. Clarity of objectives & 16.7 & 3.9 \\
\hline
\end{tabular}

Table 2. Internal consistency - Moroccan sample $(\mathrm{N}=778)$

\begin{tabular}{|l|c|}
\hline \multicolumn{1}{|c|}{ Echelles } & $\propto$ from Cronbach \\
\hline 1. Dominance & .78 \\
\hline 2. Perseverance & .66 \\
\hline 3. Resistance to stress & .78 \\
\hline 4. Sociability & .75 \\
\hline 5. Circumspection & .69 \\
\hline 6. Curiosity of mind & .67 \\
\hline 7. Acceptance of others & .71 \\
\hline 8. Dynamism & .68 \\
\hline 9. Search for approval & .61 \\
\hline 10. Conformism & .76 \\
\hline 11. Social consideration & .53 \\
\hline 12. Freedom of action & .66 \\
\hline 13. Interest in others & .65 \\
\hline
\end{tabular}




\begin{tabular}{|l|l|}
\hline 14. Taste of power & .77 \\
\hline 15. Materialism & .65 \\
\hline 16. Personal challenge & .60 \\
\hline 17. Variety / Novelty & .79 \\
\hline 18. Conviction & .66 \\
\hline 19. Organization / Method & .69 \\
\hline 20. Clarity of objectives & .62 \\
\hline
\end{tabular}

The coefficients vary from .66 (Perseverance) to .78 (Dominance and Resistance to stress) for the personality scales and from .53 (Social consideration) to .79 (Variety / Novelty) for the value scales. Out of the 271 statements, ten items have an item-note correlation $<.10(3.7 \%)$, three of which have an item-note correlation $\leq .00$.

Table 3. Inter-correlations - Moroccan sample $(\mathrm{N}=778)$

\begin{tabular}{|c|c|c|c|c|c|c|c|c|c|c|c|c|c|c|c|c|c|c|c|}
\hline \multicolumn{9}{|c|}{ Personality scales } & \multicolumn{11}{|c|}{ Value scales } \\
\hline & 1 & 2 & 3 & 4 & 5 & 6 & 7 & 8 & 9 & 10 & 11 & 12 & 13 & 14 & 15 & 16 & 17 & 18 & 19 \\
\hline 2 & .10 & 1.00 & & & & & & & & & & & & & & & & & \\
\hline 3 & .26 & .13 & 1.00 & & & & & & & & & & & & & & & & \\
\hline 4 & .30 & -.09 & -.06 & 1.00 & & & & & & & & & & & & & & & \\
\hline 5 & -.10 & .41 & .34 & -.20 & 1.00 & & & & & & & & & & & & & & \\
\hline 6 & .42 & .13 & .16 & .22 & -.22 & 1.00 & & & & & & & & & & & & & \\
\hline 7 & .19 & .31 & .50 & .10 & .24 & -.01 & 1.00 & & & & & & & & & & & & \\
\hline 8 & .37 & .26 & .06 & .19 & -.28 & .14 & -.17 & 1.00 & & & & & & & & & & & \\
\hline 9 & -.29 & -.27 & -.26 & -.08 & -.10 & -.18 & -.16 & -.25 & & & & & & 1.00 & & & & & \\
\hline 10 & -.04 & .44 & .23 & -.07 & .43 & -.14 & .29 & .01 & -.16 & 1.00 & & & & & & & & & \\
\hline 11 & -.01 & -.18 & -.14 & .09 & -.14 & .01 & -.14 & -.02 & .33 & -.25 & 1.00 & & & & & & & & \\
\hline 12 & -.18 & -.22 & -.11 & -.15 & -.27 & -.02 & -.28 & -.06 & .16 & -.25 & .05 & 1.00 & & & & & & & \\
\hline 13 & -.07 & -.02 & -.03 & .06 & .07 & .01 & .19 & -.15 & .15 & .27 & -.08 & \begin{tabular}{|l|} 
\\
\end{tabular} & 1.00 & & & & & & \\
\hline 14 & .48 & .12 & \begin{tabular}{|l}
.20 \\
\end{tabular} & .15 & -.05 & .28 & .04 & .36 & -.32 & .15 & .13 & -.01 & -.25 & 1.00 & & & & & \\
\hline 15 & -.19 & -.08 & -.06 & -.11 & .10 & -.23 & -.01 & -.16 & .17 & .05 & .13 & .00 & -.05 & -.23 & 1.00 & & & & \\
\hline 16 & .24 & .09 & .12 & .03 & -.05 & .28 & .02 & .25 & -.18 & -.04 & .09 & -.15 & -.05 & .28 & -.09 & 1.00 & & & \\
\hline 17 & -.05 & -.32 & -.14 & .03 & -.36 & .15 & -.14 & -.09 & .18 & -.41 & .07 & .34 & .03 & -.11 & .08 & \begin{tabular}{|l|}
.06 \\
\end{tabular} & 1.00 & & \\
\hline 18 & .25 & -.17 & -.04 & .10 & -.32 & .22 & -.16 & .21 & -.07 & -.26 & -.08 & .16 & -.02 & .24 & -.27 & .24 & .12 & & .00 \\
\hline 19 & -.19 & .32 & \begin{tabular}{|l|}
.05 \\
\end{tabular} & -.07 & .40 & -.31 & .17 & -.13 & -.06 & \begin{tabular}{|l|}
.46 \\
\end{tabular} & -.08 & -.25 & .06 & -.17 & .28 & -.06 & -.32 & -.26 & 1.00 \\
\hline 20 & -.05 & .23 & .10 & .01 & .31 & -.14 & .14 & -.05 & -.08 & .29 & -.13 & -.18 & .01 & .03 & .01 & -.05 & -.23 & -.01 & .38 \\
\hline
\end{tabular}

Note. 1 = Dominance, $2=$ Perseverance, $3=$ Resistance to stress, $4=$ Sociability, $5=$ Circumspection, $6=$ Curiosity of mind, $7=$ Acceptance of others, $8=$ Dynamism, $9=$ Seeking approval, $10=$ Conformism, $11=$ Social consideration, 12 = Freedom of action, $13=$ Interest in others, $14=$ Taste for power, $15=$ Materialism, $16=$ Personal challenge, $17=$ Variety $/$ Novelty, $18=$ Conviction, $19=$ Organization $/$ Method, $20=$ Clarity of objectives. $\mathrm{r} \geq .07, \mathrm{p}<.05 ; \geq .10, \mathrm{p}<.01$

The correlation coefficients vary from -.28 (Circumspection $\mathrm{x}$ Dynamism) to .50 (Resistance to stress $\mathrm{x}$ Acceptance of others) for the personality scales; from -.41 (Conformity x Variety / Novelty) to .46 (Conformity x Organization / Method) for the value scales, and from -.36 (Circumspection $\mathrm{x}$ Variety / Novelty) to .48 (Dominance $\mathrm{x}$ Taste of power) between personality and value scales. The stability of the notes was measured 
by a test-retest. Eighty people passed SOSIE a second time with an average interval of thirty days. The test-retest coefficients presented below are Bravais-Pearson correlation coefficients corrected by the Spearman-Brown formula.

Table 4. Test-retest reliability - Moroccan sample $(\mathrm{N}=80)$

\begin{tabular}{|l|r|r|r|r|r|r|r|r|r|r|r|r|r|r|r|r|r|r|r|r|}
\hline Scale & $\mathbf{1}$ & $\mathbf{2}$ & $\mathbf{3}$ & $\mathbf{4}$ & $\mathbf{5}$ & $\mathbf{6}$ & $\mathbf{7}$ & $\mathbf{8}$ & $\mathbf{9}$ & $\mathbf{1 0}$ & $\mathbf{1 1}$ & $\mathbf{1 2}$ & $\mathbf{1 3}$ & $\mathbf{1 4}$ & $\mathbf{1 5}$ & $\mathbf{1 6}$ & $\mathbf{1 7}$ & $\mathbf{1 8}$ & $\mathbf{1 9}$ & $\mathbf{2 0}$ \\
\hline $\mathrm{r}_{\mathrm{p}}$ & .86 & .72 & .80 & .79 & .84 & .76 & .87 & .81 & .64 & .70 & .74 & .78 & .75 & .81 & .68 & .73 & .79 & .71 & .85 & .79 \\
\hline
\end{tabular}

Note. The correlations were calculated from the previous version of the SOSIE (98 items).

The coefficients range from .75 to .86 for the personality scales and from .56 to .79 for the value scales, thus showing greater stability of measurements of personality traits, which is in agreement with the results of many studies in this area.

\subsection{Convergent validity}

Validity of a test can be tested using correlation studies with other tests measuring the same constructs. The validity of the SOSIE has been studied in various countries and using tests measuring personality traits and/or values.

\subsection{Correlations between the SOSIE and the WVI inventory (World Values Inventory)}

Generally speaking, work values inventory can be defined as the qualities that people seek in their work, occupation, or career. In contrast, interests may be defined as the activities through which valued qualities are realized. For example, valuing independence may call for one to be interested in managerial activities.

The values measured by the D.E. Super questionnaire (World Values Inventory, 1970) [8] come in part from the Allport-Vernon-Lindsey Study of Values (1970) [9]. Other values come from studies of satisfaction in the work of Hoppock (1935) [10]. and Centers (1948) [11]. and the theories of Darley and Hagenah (1955) [12], Fryer (1931), and Ginzberg (1951) [13]. The similarities between the list of super professional values and the professional needs and values of Dawis and Lofquist (1984) [14] provide further evidence of the content validity of the WVI. D.E. Super considers professional values to be the importance attached to tasks in general. He defines them as the qualities that people want and seek in their professional activities and circumstances. According to Super, values can be considered intrinsic or extrinsic: namely, those which are inherent and derived from the activity itself or those which result from participation in this activity. The DE Super Professional Values Questionnaire (QVP, 1970, 1991) [15] includes 15 scales for measuring the relative importance given to the following values in the context of professional activity: Creativity, Management, Achievement, Environment, Relations with hierarchy, Lifestyle, Security, Relations with colleagues, Aesthetics, Prestige, Independence, Variety, Economic advantages, Altruism and Intellectual stimulation.

The SOSIE and the WVI were administered jointly with a sample of Moroccan executives $(\mathrm{N}=53)$. The correlations are presented in table 1.5 and the PivotChart 1.1 
Table 5. Correlations between SOSIE and WVI Inventory

\begin{tabular}{|c|c|c|c|c|c|c|c|c|c|c|c|c|c|c|c|}
\hline & CR & MA & $\mathbf{R E}$ & EN & HR & LI & SE & RC & ES & PR & IN & VA & EB & $\mathbf{A L}$ & IS \\
\hline 1. Dominance & .28 & 12 & -.10 & -.12 & -.28 & -.08 & -.10 & 10 & -.02 & .07 & .23 & 24 & .18 & -.11 & 12 \\
\hline 2. Perseverance & .13 & 20 & 15 & -.16 & .09 & -.11 & 13 & -.04 & .23 & -.16 & 11 & 02 & -.17 & .09 & .21 \\
\hline 3. Resis & 23 & 16 & .07 & -.17 & -.06 & -.07 & .01 & 10 & .17 & -.15 & 18 & .08 & -.10 & -.08 & 23 \\
\hline 4. Socia & .16 & -.14 & .02 & -.02 & -.13 & -.09 & -.11 & .14 & 02 & .03 & -.10 & 21 & .03 & .01 & .02 \\
\hline 5. Circ & -.09 & .02 & .24 & .01 & .24 & -.04 & .19 & .00 & .03 & -.13 & -.06 & .17 & -.09 & .03 & .01 \\
\hline 6. Cur & .60 & -.03 & .40 & -.24 & -.10 & -.16 & -.18 & .16 & .22 & -.10 & -.18 & .40 & -.25 & .12 & .56 \\
\hline $\begin{array}{l}\text { 7. Acceptance o } \\
\text { ers }\end{array}$ & .13 & 21 & .28 & .03 & .18 & .12 & .14 & .34 & .07 & .08 & .03 & 16 & -.02 & .19 & .32 \\
\hline 8. Dynamism & .39 & 20 & 13 & .06 & -.05 & .08 & .20 & 10 & .29 & .13 & .20 & .05 & -.04 & .27 & .21 \\
\hline 9. Sea & .15 & -.28 & -.10 & .01 & .12 & -.09 & -.16 & .04 & -.30 & .01 & -.39 & -.10 & -.02 & -.20 & -.11 \\
\hline 10. Col & -.14 & -.07 & .30 & .04 & .15 & .14 & .37 & .05 & .23 & -.10 & -.25 & .01 & -.14 & .26 & .02 \\
\hline $\begin{array}{l}\text { 11. So } \\
\text { tion }\end{array}$ & .04 & .09 & .07 & .05 & .07 & .11 & .18 & .15 & -.02 & .44 & -.04 & -.16 & .07 & -.04 & -.19 \\
\hline 12. Fre & -.18 & -.22 & -.36 & .08 & -.05 & .00 & -.25 & -.21 & -.19 & -.36 & .20 & -.03 & .13 & -.36 & .07 \\
\hline 13. Int & .06 & -.21 & .23 & .18 & .12 & .16 & .15 & .17 & .33 & .01 & .04 & .09 & -.07 & .50 & .01 \\
\hline 14. $\mathrm{Ta}$ & .30 & .54 & -.10 & -.27 & -.29 & .24 & -.23 & -.12 & -.10 & .09 & .28 & .12 & .05 & -.16 & 13 \\
\hline 15. $\mathrm{M}_{\mathrm{c}}$ & -.48 & .03 & -.32 & .05 & -.12 & .10 & .22 & -.16 & -.28 & -.10 & .00 & -.11 & .32 & -.32 & -.25 \\
\hline al challenge & .25 & .28 & .15 & -.15 & -.02 & .22 & .16 & -.10 & .04 & .04 & .16 & -.14 & .10 & .19 & .15 \\
\hline 17. Va & .19 & -.14 & -.01 & -.23 & -.19 & -.12 & -.45 & .16 & -.21 & -.13 & -.14 & .19 & -.26 & .01 & .14 \\
\hline 18. Conviction & .30 & .09 & -.12 & -.12 & -.20 & .00 & -.32 & -.03 & .28 & .00 & .18 & -.08 & -.14 & .10 & -.06 \\
\hline $\begin{array}{l}\text { 19. Organization / } \\
\text { Method }\end{array}$ & -.31 & -.12 & .12 & .30 & .41 & .09 & .36 & .02 & .01 & .13 & -.19 & -.10 & .03 & .10 & -.10 \\
\hline $\begin{array}{l}\text { 20. Clarity of objec- } \\
\text { tives }\end{array}$ & .15 & -.04 & .20 & .16 & .07 & .16 & .08 & .07 & .31 & .10 & 14 & 22 & .01 & -.09 & .15 \\
\hline
\end{tabular}

Note. $\mathrm{Cr}=$ Creativity; $\mathrm{Ma}=$ Management $\mathrm{D}=$ Realization; $\mathrm{En}=$ Environment; $\mathrm{HR}=$ Relations with hierarchy; $\mathrm{Li}=$ Lifestyle; $\mathrm{Se}=$ Security; RC = Relations with colleagues; Es = Aesthetics; Pr = Pre tige; In = Independence; $\mathrm{Va}=$ Variety; $\mathrm{Eb}=$ Economic benefits; $\mathrm{Al}=$ Altruism; $\mathrm{IS}=$ Intellectual stimulation. $\mathrm{r} \geq .27, \mathrm{p}<.05$; $\mathrm{r} \geq .35, \mathrm{p}<.01$

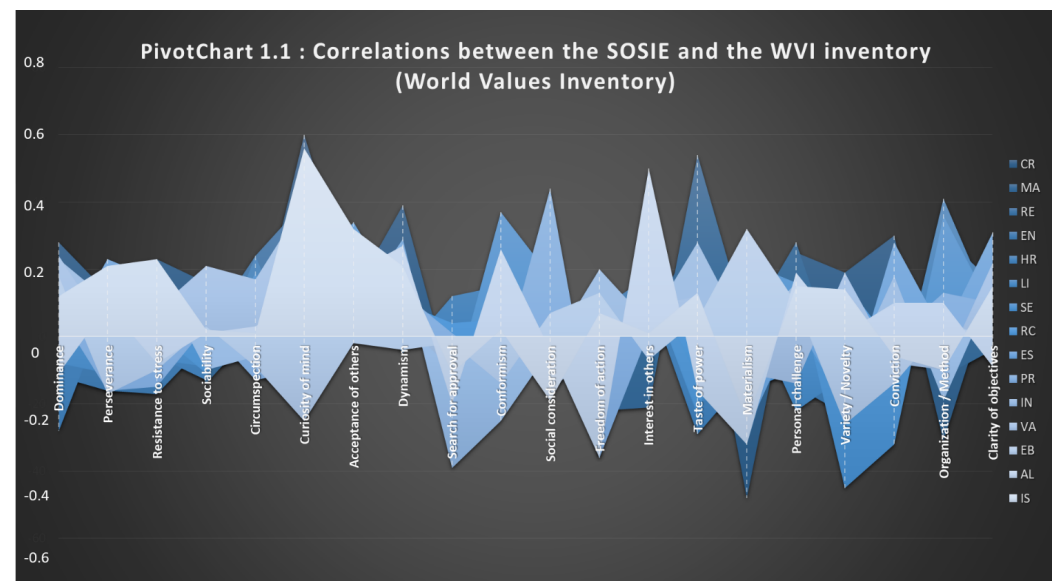

Fig. 2. PivoChart 1.1 Correlations between SOSIE and WVI Inventory 
The main correlations between the SOSIE scales and those of the WVI inventory are as follows:

- Curiosity of mind is positively correlated with Creativity (.60)

- Intellectual stimulation (.56), Realization (.40) and Variety (.40)

- Dynamism is positively correlated with Creativity (.39)

- Seeking approval is negatively correlated with Independence (-.39)

- Conformism is positively correlated with Security (.37)

- Social consideration is positively correlated with Prestige (.44)

- Freedom of action is negatively correlated with Altruism (-.36)

- Prestige (-.36) and Realization (-.36)

- Interest in others is positively correlated with Altruism (.50)

- Taste of power is positively correlated with Management (.54)

- Materialism is negatively correlated with Creativity (-.48)

- Variety / Novelty is negatively correlated with Security (-.45)

- Organization / Method is positively correlated with Relations with the hierarchy (.41) and Security (.36)

\section{Conclusion}

The interest in using digital platforms for the evaluation of executives is multiple. It resides in particular in the transformational power of work situations relating to the functions occupied by managers. Beyond their own adjustments to working conditions, the organization of the work of other actors is at stake. Having ourselves little time and no traces of activity to intervene with these executives, the gamble that is defended here is not that of an expository approach to the concepts of ergonomics, but that of becoming aware, through an interview situation of the "look-alike" type, of the challenges linked to an approach that takes into account the actual work. The use of this digital method can seem flexible (little time, no collection of traces of the activity) and allow to initiate managerial staff in ergonomics by an experience of analysis of their own activity. Yet, carried out as it has been there, it leaves school heads in a separate when re-normalizing professional rules.

Cut off from the effects of their activities on the "beneficiaries of their action" (the results of their work), the use of this method leaves executives at risk of reducing the effectiveness of the organizations they lead, of managing by reducing the elements of analysis for their only job, even their only activity. The negative effects on the quality of work of peer debates have already been shown (Veyrac \& Blanc, 2015).

To compensate for this, an introduction of data on "results" in the analysis of work appears necessary, an introduction which in the education profession is rarely observed in Morocco. One function that the ergonomist can take on is to organize the conditions for a decentralization of the analysis of work between peers. Conceiving situations favoring interprofessional understanding of working conditions seems to be a way of mitigating the negative effects of professional inter-self-likely to be produced by setting up co-analyzes of activity that are too brief. 


\section{$5 \quad$ References}

[1] Gordon, L.V. (1956). Gordon Personal Inventory: GPI. Yonkers-on-Hudson. New York: World Book.

[2] Gordon, L.V. (1953). Gordon Personal Profile: GPP. Yonkers-on-Hudson. New York: World Book.

[3] Gordon, L.V. (1967). Survey of Personal Values: SPV. Paris: ECPA.

[4] Gordon, L.V. (1975). Survey of Interpersonal Values: SIV. Paris: ECPA.

[5] Astalini, Darmaji, Wawan Kurniawan, Khairul Anwar, Dwi Agus Kurniawa (2019). Effectiveness of Using E-Module and E-Assessment. International Journal of Interactive Mobile Technologies (iJIM). 13(9), 21-39. https://online-journals.org/index.php/i-jim/article/view/ 11016. https://doi.org/10.3991/ijim.v13i09.11016

[6] D. Baneres, X. Baró, A-E. Guerrero-Roldán, M. E. Rodríguez (2016). Adaptive e-Assessment System: A General Approach. International Journal of Emerging Technologies in Learning (iJET). 11(7), 16-23. https://online-journals.org/index.php/i-jet/article/view/58 88. https://doi.org/10.3991/ijet.v11i07.5888

[7] Marjan Gusev, Sasko Ristov, Goce Armenski, Goran Velkoski, and Krste Bozinoski (2013). E-Assessment Cloud Solution: Architecture, Organization and Cost Model. International Journal of Emerging Technologies in Learning (iJET). 8(2), 55-64. https://online-journals.org/index.php/i-jet/article/view/2783. https://doi.org/10.3991/ijet.v8is2.2783

[8] Super, D. E. (1970). Work Values Inventory. Boston: Houghton Mifflin.

[9] Allport, G.W., Vernon, P.E., et Lindsey, G. (1970). Study of values. Boston: HoughtonMifflin.

[10] Hoppock. R. (1935). Job satisfaction. New York: Harper \& Row.

[11] Centers, R. (1948). Motivational aspects of occupational stratification. Journal of Social Psycholo-gy, 28, 187-217.

[12] Darley, J. G., et Hagenah, T. (1955). Vocational interest measurement: Theory and practice. Minneapolis, MN: University of Minnesota Press. https://doi.org/10.1016/b978-0-08013391-1.50029-8

[13] Fryer, D. (1931). The measurement of interests in relation to human adjustment. New York: Holt et Co.

[14] Dawis, R. V., et Lofquist, L. H. (1984). A psychological theory of work adjustment. Minneapolis, MN: University of Minnesota Press.

[15] Super, D.E. (1991). Questionnaire des Valeurs Professionnelles : QVP. Paris

\section{Authors}

Yassir Aichi works at the Laboratory of Physical Chemistry of Materials in Ben M'Sick Faculty of Sciences of Hassan II University of Casablanca state BP 5366 Maarif city Casablanca of Morocco. yassiraichi@gmail.com

Mustapha Bassiri works in Ecole Normale Supérieure de Casablanca ENS of Hassan II University of Casablanca state BP 5366.

Said Benmokhtara works for the Laboratory of Physical Chemistry of Materials, Ben M'Sick Faculty of Sciences, Hassan II University of Casablanca, BP 5366 Maarif, Casablanca, Morocco.

Said Belaaouad works for the Laboratory of Physical Chemistry of Materials, Ben M'Sick Faculty of Sciences, Hassan II University of Casablanca, BP 5366 Maarif, Casablanca, Morocco.

Article submitted 2020-05-21. Resubmitted 2020-07-21. Final acceptance 2020-09-12. Final version published as submitted by the authors. 